\title{
A Thermal Model for Piloted Ignition of Wood Including Variable Thermophysical Properties
}

\section{MARC JANSSENS}

National Forest Products Association

1250 Connecticut Avenue NW, Suite 200

Washington, DC 20036, USA

\section{ABSTRACT}

A simplified thermal model of piloted ignition is formulated. The model equations are then solved numerically for the thermally thick case using a finite difference technique. A systematic analysis of some solutions leads to a functional relationship between ignition time $t_{i g}$ and irradiance $\dot{q}_{e}^{\prime \prime}$, suitable for correlation of piloted ignition data. This suggests plotting ignition data in a graph of $\left(t_{i g}\right)^{-0.547}$ versus $\dot{q}_{e}^{\prime \prime}$. The critical irradiance $\dot{q}_{c r}^{\prime \prime}$ is then found as the intercept with the abscissa of a straight-line fit through the data. An apparent $k \rho c$ can be obtained from the slope of the regression line. Theoretical calculations show that this apparent $k \rho c$ for wood products is evaluated at a temperature approximately halfway between $T_{\infty}$ and $T_{i g}$. The suggested correlating procedure is applied to measurements for six oven dry wood species obtained in the Cone Calorimeter.

KEYWORDS: wood, piloted ignition, mathematical model, thermal inertia, Cone Calorimeter

\section{NOMENCLATURE}

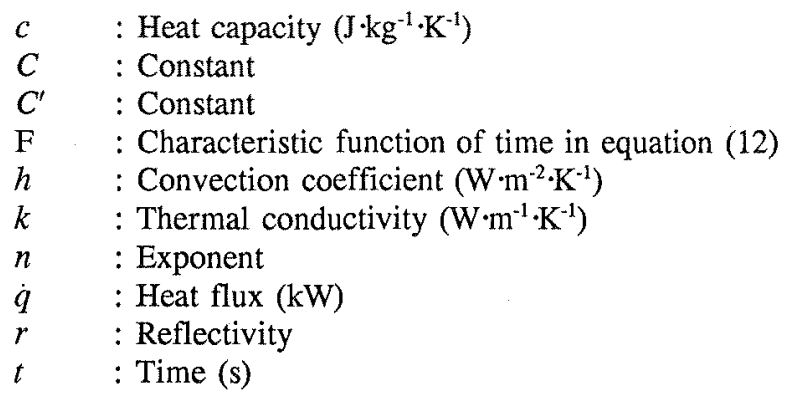




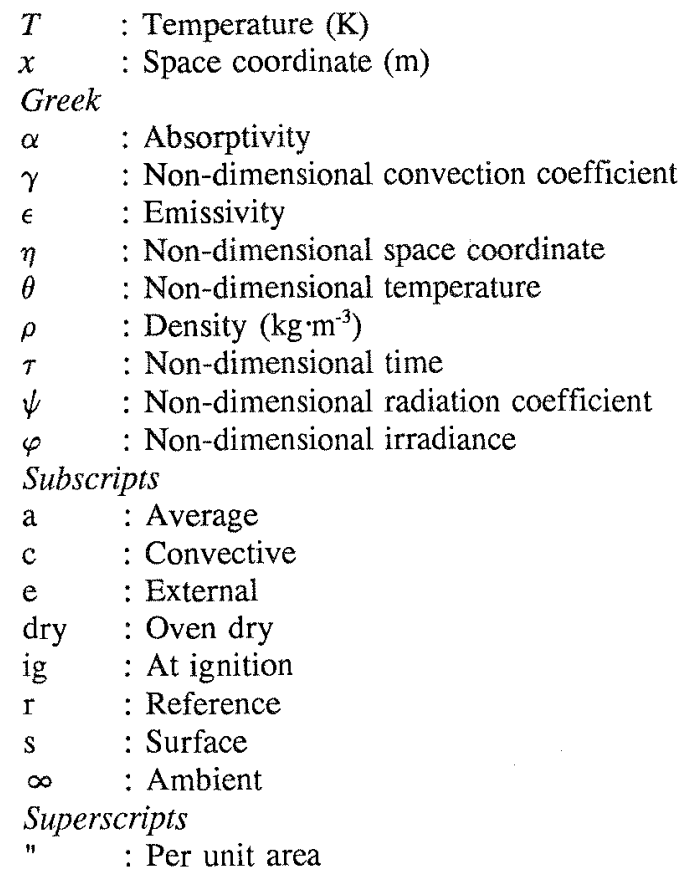

\section{INTRODUCTION}

Piloted ignition of wood has been studied extensively over the past 40 to 50 years. The time to piloted ignition, $t_{i g}$, of a certain material is primarily a function of the incident heat flux. Ignitability at a given heat flux level depends on the thermal properties of the material, in particular the thermal inertia $k \rho c$. In previous work, small samples of wood were usually exposed to the radiant heat flux produced by a gas panel or an electric heater, and $t_{i g}$ was measured as a function of the irradiance, $\dot{q}_{e}^{\prime \prime}$. Many investigators correlated such data using a power law of the following form

$$
\left(\dot{q}_{e}^{\prime \prime}-\dot{q}_{c r}^{\prime \prime}\right) t_{i g}^{n}=C
$$

where $C$ is constant for a given material and $q_{c r}^{\prime \prime}$ is the critical irradiance below which piloted ignition under practical conditions no longer occurs. Lawson and Simms suggested $n=2 / 3$ and correlated $C$ with $k \rho c$ values obtained from the literature [1]. Buschman correlated $n$, $\dot{q}_{c r}^{\prime \prime}$, and $C$ with literature values for k $\rho \mathrm{c}$ [2]. Magnusson and Sundström suggested an inverse correlating procedure, i.e., a technique to derive an apparent $k \rho c$ from the correlation of piloted ignition data [3]. However, this proposal was not very practical because it required measurement of surface temperature. Quintiere and Harkleroad developed another procedure to obtain an apparent $k \rho c$, without the need for such tedious temperature measurements [4].

The thermal properties used by Simms and Buschman were evaluated at ambient temperature. Both $k$ and $c$ of wood products, however, are strongly dependent on 
temperature. Intuitively one expects an apparent $k \rho c$ to correspond to a temperature somewhere between $T_{\infty}$ and the surface temperature at ignition, $T_{i g}$, perhaps closer to the latter. The results presented below confirm that this is indeed the case.

\section{MATHEMATICAL MODEL. OF PILOTED IGNITION}

A large number of mathematical models of the piloted ignition problem have been developed with varying degrees of complexity. Some models include gas phase diffusion and mixing [5]. Others consider only the solid phase, but include pyrolysis and other chemical reactions [6]. The model considered in this article is less sophisticated, but still includes many features not addressed by other thermal models. It is based on the following assumptions

- Heat flow in the solid is one-dimensional, i.e., perpendicular to the exposed surface.

- Chemical effects prior to ignition are negligible, i.e., no pyrolysis.

- Convective heat transfer between fuel vapors and the porous solid is negligible.

- Ignition occurs when the surface reaches a given material-dependent temperature. This criterion is acceptable for engineering purposes, as shown experimentally in [7].

- The material is opaque. Although wood is in fact not completely opaque, especially at small wavelengths, it is much less transparent than many other materials.

- Kirchoff's law is valid for the total $\alpha, \epsilon$ and $r$, i.e., $\alpha=\epsilon=1-r$.

- The values for $\alpha, \epsilon$ and $r$ are constant between the start of exposure and ignition.

- The heat losses from the surface are partly radiative and partly convective with a constant convection coefficient.

- The specimens behave as a semi-infinite solid. All wood samples tested have a thickness of more than $16 \mathrm{~mm}$ and may be considered thermally thick [8].

Under these assumptions, the piloted ignition problem becomes a purely thermal problem. It has the following mathematical form

\section{Energy Conservation}

$$
\frac{\partial}{\partial x}\left(k \frac{\partial T}{\partial x}\right)=\rho c \frac{\partial T}{\partial t},
$$

Boundary Condition $(x=0)$

$$
-k \frac{\partial T}{\partial x}=\varepsilon \dot{q}_{e}^{\prime \prime}-h_{c}\left(T_{s}-T_{\infty}\right)-\epsilon \sigma\left(T_{s}^{4}-T_{\infty}^{4}\right)
$$

Boundary Condition $(x \rightarrow \infty)$

$$
-k \frac{\partial T}{\partial x}=0
$$

Initial Condition $(t=0, x \geq 0)$

$$
T=T_{\infty} \text {. }
$$


The absorbed part of the critical irradiance, $\dot{q}_{c r}^{\prime \prime}$, is equal to the heat losses from the surface at ignition because below this irradiance level the surface temperature can never reach $T_{i g}$, even for $t \rightarrow \infty$. Consequently, a total heat transfer coefficient from the surface at ignition $h_{i g}$ can be defined as

$$
€ \dot{q}_{c r}^{\prime \prime} \equiv h_{c}\left(T_{i g}-T_{\infty}\right)+\varepsilon \sigma\left(T_{i g}^{4}-T_{\infty}^{4}\right) \equiv h_{i g}\left(T_{i g}-T_{\infty}\right)
$$

The objective is to find a solution of (2)-(5) in a form suitable for the correlation of experimental data and to infer an apparent value for $k \rho c$. The latter is a constant representative average over the temperature range between $T_{\infty}$ and $T_{i g}$. In order to obtain such a solution, $k$ and $c$ are assumed constant. The following non-dimensional variables can then be defined

$$
\begin{gathered}
\theta \equiv \frac{T-T_{\infty}}{T_{i g}-T_{\infty}}, \tau \equiv \frac{h_{i g}^{2} t}{k \rho c}, \quad \eta \equiv \frac{x h_{i g}}{k}, \quad \varphi=\frac{\dot{q}_{e}^{\prime \prime}}{\dot{q}_{c r}^{\prime \prime}} \\
\gamma \equiv \frac{h_{c}}{h_{i g}}, \quad \Psi \equiv \frac{\sigma\left(T_{i g}-T_{\infty}\right)^{4}}{\dot{q}_{c r}^{\prime \prime}}, \quad \text { and } \quad \theta_{\infty} \equiv \frac{T_{\infty}}{T_{i g}-T_{\infty}} .
\end{gathered}
$$

The resulting non-dimensional model equations are

Energy Conservation

$$
\frac{\partial^{2} \theta}{\partial \eta^{2}}=\frac{\partial \theta}{\partial \tau}
$$

Boundary Condition $(\eta=0)$

$$
-\frac{\partial \theta}{\partial \eta}-\varphi-\gamma \theta_{s}-\psi\left(\left(\theta_{s}+\theta_{\infty}\right)^{4}-\theta_{\infty}^{4}\right),
$$

Boundary Condition $(\eta \rightarrow \infty)$

$$
-\frac{\partial \theta}{\partial \eta}=0
$$

Initial Condition $(\tau=0, \eta \geq 0)$

$$
\theta=0 \text {. }
$$

\section{SOLUTION WITH LINEARIZED HEAT LOSSES}

The solution of (8)-(11) with linearized surface heat losses $(\gamma=1$ and $\psi=0)$ can be found in standard textbooks on heat conduction e.g., [9], p.276. At the exposed surface $\eta=0$, this yields a fairly simple expression 
Equation (12) shows that $\theta_{\mathrm{s}} / \varphi$ is independent of irradiance. The complimentary error function cannot be calculated analytically, but may be obtained numerically. Many investigators have based their correlation of piloted ignition data on equation (12). Unfortunately, due to the presence of the complementary error function, the functional form of (12) is not directly suitable for correlating purposes. Therefore, approximations based on a truncated series expansion have been used instead [1]-[4]. These approximations are only valid over a limited range of $\tau$ values. Outside this range, agreement with $\mathrm{F}(\tau)$ is poor.

It is remarkable that a number of researchers have been successful at correlating piloted ignition data using a power law of the form of equation (1). If the assumptions are valid that ignition occurs at a given surface temperature and that surface heat losses are approximately linear, (1) indicates that $\mathrm{F}\left(\tau_{\text {ig }}\right)$ can be expressed as

$$
F\left(\tau_{i g}\right)=\frac{1}{\varphi} \approx \frac{1}{1+C^{\prime} \tau_{i g}^{-n}}
$$

A non-linear least squares regression fit of a function of the form (13) to the original function $\mathrm{F}(\tau)$ in (12) over a range of $\tau$ values from 0 to $20^{1}$ gives the following result

$$
F(\tau) \approx \frac{1}{1+0.73 \tau^{-0.547}}
$$

The optimum value for $n$ is 0.547 which is very close to 0.5 , as suggested by a number of authors (Quintiere [4], Mikkola and Wichman [8], Abu-Zaid [10], Panagiotou and Delichatsios [11]). The functional form (14), although quite accurate (less than $1 \%$ error over the range $0<\tau<20$ ), is remarkably simple. It suggests plotting ignition data as $\left(t_{i g}\right)^{-0.547}$ versus irradiance $\dot{q}_{e}^{\prime \prime}$. The critical flux is then found as the intercept with the abscissa and $k \rho c$ can be calculated from the slope. A question remains whether (14) is still applicable if surface heat losses are non-linear, $\epsilon<1$, and thermal properties vary with temperature.

\section{NON-LINEAR SURFACE HEAT LOSSES AND $\epsilon \leq 1$}

A numerical finite difference solution to equations (8)-(11) is used to obtain the nondimensional time $\tau_{\mathrm{ig}}$ to reach ignition temperature, $T_{i g}$, on the surface for $\epsilon=0.6,0.7,0.8$, 0.9 and 1 . The calculations are performed for $T_{i g}=250^{\circ} \mathrm{C}, 350^{\circ} \mathrm{C}, 450^{\circ} \mathrm{C}$ and $550^{\circ} \mathrm{C}$. A power law of the form of (13) is used for a curve fit of the calculated results. Table 1 lists the values for $C^{\prime}$ and $n$ resulting in the best fit for each of the ignition temperatures considered and $\epsilon=0.6$ as an example. Note that $\dot{q}_{c r}^{\prime \prime}$ in column 2 is calculated from (6) with $\epsilon=0.6$ and $h_{c}=15 \mathrm{~W} \cdot \mathrm{m}^{-2} \cdot \mathrm{K}^{-1}$ [4]. As in the case of linear heat losses, 0.73 and 0.547 seem

${ }^{1}$ With equation (7) and the values for $k \rho c$ and $h_{\mathrm{ig}}$ of Table 4 , the real time corresponding to $\tau=20$ exceeds 24 minutes for all materials tested. Since the test time was always less than 20 minutes, the range of $\tau$ chosen for the curve fit is appropriate. 
to be very reasonable averages for $C^{\prime}$ and $n$ respectively. Thus, the conclusion is that the functional relationship (14), valid for linearized surface heat losses, may also be used for the case of non-linear heat losses, and $\epsilon \leq 1$, at least when $h_{c}$ is of the order of $15 \mathrm{~W} \cdot \mathrm{m}^{-2} \cdot \mathrm{K}^{-1}$ and $h_{i g}$ is used to define $\tau$ (see Eq. (7)).

TABLE 1. Values for power law relationship (13) with $\epsilon=0.6$

\begin{tabular}{cccc}
\hline$T_{i g}\left({ }^{\circ} \mathrm{C}\right)$ & $\dot{q}_{c r}^{\prime \prime}\left(\mathrm{kW} \cdot \mathrm{m}^{-2}\right)$ & $C^{\prime}$ & $n$ \\
\hline 250 & 9.6 & 0.77 & 0.530 \\
350 & 16.4 & 0.74 & 0.544 \\
450 & 25.8 & 0.73 & 0.551 \\
550 & 38.9 & 0.70 & 0.542 \\
\hline
\end{tabular}

THERMAL PROPERTIES OF WOOD

In all calculations so far, $k$ and $c$ are assumed to be constant. For wood products, as for many other building materials, thermal properties are temperature dependent. Maku found the following (convenient) temperature effect on the thermal conductivity of oven-dry wood [12]

$$
k(T)=k_{r} \frac{T}{T_{r}}
$$

where $k_{r}$ is the thermal conductivity at the reference temperature $T_{r}$ in $\mathrm{W} \cdot \mathrm{m}^{-1} \cdot \mathrm{K}^{-1}$; it can be calculated from MacLean's correlation, for $T_{r}=293 \mathrm{~K}$ [13]

$$
k_{r}=0.0237+2 * 10^{-4} * \rho_{d r y} .
$$

Koch found that the heat capacity of some oven dry wood species is also proportional to the absolute temperature [14]

$$
c(T)=c_{r} \frac{T}{T_{r}}
$$

where $c_{r}$ is the heat capacity in $\mathrm{J} \cdot \mathrm{kg}^{-1} \cdot \mathrm{K}^{-1}$ at the reference temperature $T_{r} ; c_{r}$ is independent of density and equal to $1200 \mathrm{~J} \cdot \mathrm{kg}^{-1} \cdot \mathrm{K}^{-1}$ at $T_{r}=293 \mathrm{~K}$.

\section{SOLUTION WITH TEMPERATURE-DEPENDENT THERMAL PROPERTIES}

A similar numerical solution as for (8)-(11) is used to solve equations (2)-(5) with temperature-dependent $k$ and $c$. Calculations are performed for a material with density $\rho_{\text {dry }}=500 \mathrm{~kg} \cdot \mathrm{m}^{-3}, \epsilon=1$ and $T_{i g}$ ranging from $250^{\circ} \mathrm{C}$ to $550^{\circ} \mathrm{C}$. Equations (15)-(17) are used to obtain $k$ and $c$ as a function of temperature. Plotted in a graph of $\log \left(t_{i g}\right)$ versus $\log \left(\dot{q}_{e}^{\prime \prime}-\dot{q}_{c r}^{\prime \prime}\right)$, the results at any of the ignition temperatures considered approximately follow a straight line. Therefore, equation (13) is applicable, even if $k$ and $c$ are temperature- 
dependent. The value for $n$ ranges from 0.539 to 0.561 , depending on $T_{\mathrm{ig}}$. Thus, $n=0.547$ still appears to be a good average and equations of the following form can be used to correlate the calculated results

$$
\dot{q}_{e}^{\prime \prime}-\dot{q}_{c r}^{\prime \prime}\left[1+0.73\left(\frac{k \rho c}{h_{i g}^{2} t_{i g}}\right)^{0.547}\right] \text { or } \varphi-1+0.73\left(\frac{1}{\tau_{i g}}\right)^{0.547} \text {. }
$$

An apparent $k \rho c$ value may be obtained from the slope of a linear fit according to (18) while $\dot{q}_{c r}^{\prime \prime}$ follows from the intercept with the abscissa. The results for four values of $T_{\mathrm{ig}}$ are presented in Table 2. Again, extrapolated $\dot{q}_{c r}^{\prime \prime}$ values in column 3 are close to the exact values in column 2. The $k \rho c$ values in column 5 are apparent values, i.e., averages for which the solution of the piloted ignition problem with constant $k$ and $c$ is approximately equal to the solution of the problem with temperature-dependent $k$ and $c$.

TABLE 2. Correlation according to (18) with temperature-dependent $k$ and $c$

\begin{tabular}{cccccc}
\hline $\begin{array}{c}\text { Exact } \\
T_{i g}\left({ }^{\circ} \mathrm{C}\right)\end{array}$ & $\begin{array}{c}\text { Exact } \\
\dot{q}_{c r}^{\prime \prime}\left(\mathrm{kW} \cdot \mathrm{m}^{-2}\right)\end{array}$ & $\begin{array}{c}\text { Extrapolated } \\
\dot{q}_{c r}^{\prime \prime}\left(\mathrm{kW} \cdot \mathrm{m}^{-2}\right)\end{array}$ & $\begin{array}{c}k_{r} \rho c_{r} \\
\left(\mathrm{~kJ}^{2} \cdot \mathrm{m}^{-4} \cdot \mathrm{K}^{-2} \cdot \mathrm{s}\right)\end{array}$ & $\begin{array}{c}k \rho c \text { from slope } \\
\left(\mathrm{kJ}^{2} \cdot \mathrm{m}^{-4} \cdot \mathrm{K}^{-2} \cdot \mathrm{s}\right)\end{array}$ & $\theta_{\mathrm{a}}$ \\
\hline 250 & 7.3 & 7.4 & 0.074 & 0.135 & 0.45 \\
350 & 13.1 & 12.9 & 0.074 & 0.189 & 0.53 \\
450 & 21.5 & 21.2 & 0.074 & 0.229 & 0.51 \\
550 & 33.6 & 33.2 & 0.074 & 0.269 & 0.50 \\
\hline
\end{tabular}

One would expect these apparent values to be at some temperature between $T_{r}$ and $T_{i g}$. This temperature, denoted as $T_{a}$, can be found from the ratio of $k \rho c$ to $k_{r} \rho c_{r}$, using (15)-(17)

$$
\frac{k \rho c}{k_{r} \rho c_{r}}=\frac{k_{r} \frac{T_{a}}{T_{r}} \rho c_{r} \frac{T_{a}}{T_{r}}}{k_{r} \rho c_{r}}=\left(\frac{T_{a}}{T_{r}}\right)^{2} .
$$

Thus, $T_{a}$ is equal to the square root of the aforementioned ratio multiplied by the reference temperature $T_{r}$. This temperature may also be expressed in a non-dimensional form with the definition of $\theta$ in (7)

$$
\theta_{a}=\frac{T_{a}-T_{\infty}}{T_{i g}-T_{\infty}}
$$

Column 6 in Table 2 shows $\theta_{\mathrm{a}}$ values with $T_{a}$ calculated from the ratio of $k \rho c$ in column 5 to $k_{r} \rho c_{r}$ in column 4 . The average $\theta_{\mathrm{a}}$ is about 0.5 . This means that apparent $k \rho c$ values, as inferred from the correlation of piloted ignition data of wood, are evaluated at a temperature, $T_{a}$, approximately halfway between the reference (close to ambient $T_{\infty}$ ) and the ignition temperature, $T_{i g}$. Of course, this remarkable result is obtained for a particular material, i.e., a wood product with oven dry density $500 \mathrm{~kg} \cdot \mathrm{m}^{-3}$ and relatively simple 
dependencies on temperature of $k$ and $c$, characteristic for wood. However, the correlation of experimental data presented below indicates that $\theta_{\mathrm{a}}=0.5$ is equally valid for other densities.

\section{CORRELATION OF SOME EXPERIMENTAL DATA}

\section{Materials Tested}

The time to piloted ignition was measured for six oven-dry wood species in the Cone Calorimeter [15] over a range of irradiance levels between 15 and $45 \mathrm{~kW} \cdot \mathrm{m}^{-2}$. Table 3 lists the names of the species tested, the oven-dry density $\rho_{\text {dry }}$ and the mean thickness $L$ of the specimens

TABLE 3. Wood species tested

\begin{tabular}{llcc}
\hline Common name & Botanical name & $\rho_{\mathrm{dry}}\left(\mathrm{kg} \cdot \mathrm{m}^{-3}\right)$ & $L(\mathrm{~mm})$ \\
\hline Western redcedar & Thuja plicata & 330 & 17.0 \\
Redwood & Sequoia sempervirens & 430 & 19.0 \\
Radiata pine & Pinus radiata & 460 & 17.5 \\
Douglas fir & Pseudotsuga menziesii & 465 & 16.8 \\
Victorian ash & Eucalyptus delegatensis & 640 & 17.2 \\
Blackbutt & Eucalyptus pilularis & 810 & 17.4 \\
\hline
\end{tabular}

The first four species are softwoods, the remaining two are hardwoods. Western redcedar, redwood and Douglas fir are North American species, and the remaining species are Australian.

\section{Correlation of Results}

The ignition tests in the Cone Calorimeter were conducted in the vertical orientation. For many specimens, $T_{i g}$ was measured with 5 mil $(0.127 \mathrm{~mm})$ thermocouples attached to the surface. Table 4 shows average ignition temperatures and some related quantities.

TABLE 4. $T_{i g}$ and related quantities measured in the Cone Calorimeter

\begin{tabular}{lcccc}
\hline Species & $T_{i g}(\mathrm{~K})$ & $\dot{q}_{c r}^{\prime \prime}\left(\mathrm{kW} \cdot \mathrm{m}^{-2}\right)$ & $h_{i g}\left(\mathrm{~W} \cdot \mathrm{m}^{-2} \cdot \mathrm{K}^{-1}\right)$ & $k \rho c\left(\mathrm{~kJ}^{2} \cdot \mathrm{m}^{-4} \cdot \mathrm{K}^{-2} \cdot \mathrm{s}\right)$ \\
\hline Western redcedar & 627 & 13.3 & 34.9 & 0.087 \\
Redwood & 637 & 14.0 & 35.9 & 0.141 \\
Radiata pine & 622 & 12.9 & 34.6 & 0.156 \\
Douglas fir & 623 & 13.0 & 34.6 & 0.158 \\
Victorian ash & 584 & 10.4 & 31.5 & 0.260 \\
Blackbutt & 573 & 9.7 & 30.6 & 0.393 \\
\hline
\end{tabular}




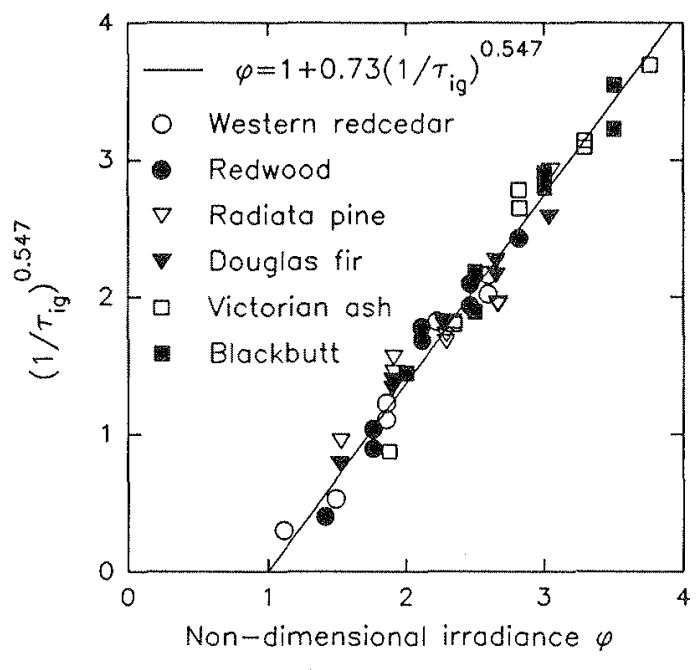

FIGURE 1 Correlation of some experimental data
The quantities $\dot{q}_{c r}^{\prime \prime}$ and $h_{i g}$ are calculated from (6) using the average measured $T_{i g}$ from column 2 of Table 4 . A value of $13.5 \mathrm{~W} \cdot \mathrm{m}^{-2} \cdot \mathrm{K}^{-1}$ is used for $h_{c}$, representative for the Cone Calorimeter in the vertical orientation [16]. Wesson measured absorptivity for a large number of wood species [17]. He found the value for a grey or black radiant heat source to be independent of species and equal to 0.76 . However, all his measurements were made at ambient temperature. As wood is heated, its surface darkens and emissivity is close to unity just prior to ignition [18]. Therefore, an average value of $\epsilon=0.88$ is used.

All piloted ignition data can now be correlated using equation (18). The result is shown in Figure 1. The solid line represents (18) in non-dimensional form. The data points are quite close to the line, but there is some inevitable scatter due to slight variances in specimen properties (density) and test conditions.

\section{CONCLUSIONS}

Piloted ignition data obtained in the Cone Calorimeter, or similar bench-scale apparatuses, may be correlated with the following formulas

$$
\dot{q}_{e}^{\prime \prime}=\dot{q}_{c r}^{\prime \prime}\left[1+0.73\left(\frac{k \rho c}{h_{i g}^{2} t_{i g}}\right)^{0.547}\right] \text { or } \varphi=1+0.73\left(\frac{1}{\tau_{i g}}\right)^{0.547} \text {. }
$$

The critical irradiance, $\dot{q}_{c r}^{\prime \prime}$, can be found as the intercept with the abscissa of a straight-line fit through the data in a graph of $\left(1 / t_{\mathrm{ig}}\right)^{0.547}$ versus irradiance $\dot{q}_{e}^{\prime \prime}$. An apparent $k \rho c$ is obtained from the slope of the line. For wood products, the apparent value corresponds to a temperature halfway between ambient and $T_{i g}$.

The results obtained so far are for oven dry thermally thick wood species. Further work is needed to determine whether the conclusions presented here can be extended to thin and wet wood specimens and board products such as plywood or particle board. 


\section{ACKNOWLEDGEMENT}

The work reported in this article was done while the author was a Research Associate for the National Forest Products Association at the Center for Fire Research of NIST. The author gratefully acknowledges the assistance of Dr. S. Yusa as a guest worker from BRI at NIST in the preparation and testing of the Cone Calorimeter specimens.

\section{REFERENCES}

1. Lawson, D. and Simms, D., The Ignition of Wood by Radiation. British Journal of Applied Physics, 3 (1952) 288-292.

2. Buschman, A., Ignition of Some Woods Exposed to Low Level Thermal Radiation. National Bureau of Standards, Project No. 1002-11-10427, Technical Report No. 1, Gaithersburg, MD, 1961.

3. Magnusson, S.E., and Sundström, B., Combustible Linings and Room Fire Growth. ASTM STP 882, Philadelphia, 1985, 45-69.

4. Quintiere, J., and Harkleroad, M., New Concepts for Measuring Flame Spread Properties. NBSIR 84-2943, Gaithersburg, MD, 1984.

5. Tzeng, L., Atreya, A., and Wichman, I., A One-Dimensional Model of Piloted Ignition. Combustion \& Flame, 80 (1990) 94-107.

6. Vandevelde, P., Les Paramètres Fondamentaux qui Déterminent l' Inflammabilité des Matériaux (Fundamental Properties Controlling Ignition Behavior of Materials). VFDB, 5th International Fire Protection Seminar, Vol. 1, 1976, pp. 99-111.

7. Atreya, A., Pyrolysis, Ignition and Fire Spread on Horizontal Surfaces of Wood. Ph.D.Thesis, Harvard University, Cambridge, MA, USA, May 1983.

8. Mikkola, E., and Wichman, I., On the Thermal Ignition of Combustible Materials. J. of Fire \& Materials, 14 (1990).

9. Öziçik, N., Heat Conduction. J.Wiley \& Sons, New York, 1985.

10. Abu-Zaid, M., Effect of Water on Ignition of Cellulosic Materials. Ph.D. Thesis, Michigan State University, East Lansing, MI, USA, 1988.

11. Panagiotou, T., and Delichatsios, M., A Numerical Solution for the Surface Temperature Rise History of a Material including Surface Reradiation Losses. FMRC J.I.OQOJI.BU, Factory Mutual Research Center, Norwood, MA, USA, 1989.

12. Maku, T., Studies of the Heat Conduction in Wood. Wood Research Bulletin, Wood Research Institute, Kyoto, Japan, 13 (1954) 1-80.

13. MacLean, J., Thermal Conductivity of Wood. Trans. Amer. Soc. Heat. Vent. Engrs., 13 (1941) 380-391.

14. Koch, Specific Heat of Oven Dry Spruce, Pine Wood and Bark. Wood Science 1 (1969) pp. 203-214.

15. American Society for Testing and Materials, E-1354-90: Standard Test Method for Heat and Visible Smoke Release Rates for Materials and Products Using an Oxygen Consumption Calorimeter. Annual Book of ASTM Standards, 04.07 (1990).

16. Janssens, M., Mathematical Model to Predict the Contribution of Wood to Fire Growth. Ph.D. Thesis, University of Gent, Gent, Belgium, 1991.

17. Wesson, H., The Piloted Ignition of Wood under Radiant Heat. Ph.D. Thesis, University of Oklahoma, Norman, OK, USA, 1971.

18. Melinek, S., The Darkening of Irradiated Wood Surfaces. F.R. Note No. 738, Fire Research Station, Borehamwood, UK, 1968. 